\title{
Highly Selective Endothelin-1 Receptor A Inhibition Prevents Bleomycin-Induced Pulmonary Inflammation and Fibrosis in Mice
}

\author{
Nikolaos Manitsopoulos ${ }^{a}$ loanna Nikitopoulou ${ }^{a}$ Nikolaos A. Maniatis ${ }^{a, c}$ \\ Christina Magkou $^{d}$ Anastasia Kotanidou, $^{a, b}$ Stylianos E. Orfanos ${ }^{a, c}$ \\ ${ }^{a}$ GP Livanos and M Simou Laboratories, 1st Department of Critical Care Medicine \& Pulmonary Services, Evangelismos \\ Hospital, University of Athens Medical School, ${ }^{\mathrm{b}} 1$ st Department of Critical Care Medicine \& Pulmonary Services, \\ Evangelismos Hospital, University of Athens Medical School, '2nd Department of Critical Care, "Attikon" Hospital, \\ University of Athens Medical School, and d Department of Pathology, Evangelismos Hospital, Athens, Greece
}

\section{Keywords}

Inflammation · Fibrosis · Bleomycin · Endothelin-1 ·

Sitaxentan · Lung function

\begin{abstract}
Background: Pulmonary fibrosis is a chronic disease, which progressively leads to respiratory failure and ultimately death. Endothelin-1 (ET-1), a vasoconstrictor secreted by endothelial cells, promotes vasoconstriction by activation of its receptors $A$ and $B$. Objectives: We addressed the role of highly selective ET-1 receptor $A(E T A)$ inhibition in the pathogenesis of experimental pulmonary fibrosis by bleomycin (BLM). Methods: BLM sulfate $(2 \mathrm{U} / \mathrm{mL})$ or saline was intratracheally administered to C57/BI6 mice (4 groups; $n=5-11$ / group). Pretreatment with the highly selective ETA receptor inhibitor sitaxentan ( $15 \mathrm{mg} / \mathrm{kg} /$ day) was started 1 day prior to BLM injection and continued for the duration of the experiment. Lung mechanics were assessed prior to sacrifice at days 7, 14, and 21 after BLM, followed by procurement of bronchoalveolar lavage fluid (BALF), blood, and lung tissue samples. Results: Time-dependent effects of BLM exposure included decreased static compliance and increased lung elastance, airspace inflammation and microvascular permeability, histological acute lung injury and fibrosis, and lung
\end{abstract}

collagen deposition. Pretreatment with highly selective ETA receptor inhibitor had no adverse effect on control mice but improved lung mechanics and lung injury score in addition to decreasing BALF pleocytosis, protein content, and collagen deposition in BLM-treated mice. Mortality from BLM reached $40 \%$ and occurred primarily during the inflammatory stage of the model but was abrogated by sitaxentan pretreatment. Conclusions: We conclude that in our BLMinduced pulmonary fibrosis model, prophylactic highly selective ETA inhibition improves survival, preserves lung function, attenuates lung injury, and reduces collagen deposition.

(c) 2017 S. Karger AG, Base

\section{Introduction}

Idiopathic pulmonary fibrosis (IPF), a chronic and progressive scarring process of the lung [1], is associated with a poor prognosis, with the majority of patients dying of respiratory failure within 2-4 years from diagnosis [2, 3 ]. The pathogenesis of IPF is not fully understood. The

N. Manitsopoulos and I. Nikitopoulou contributed equally to this work.

\section{KARGER}

(C) 2017 S. Karger AG, Basel

E-Mail karger@karger.com

www.karger.com/res
Dr. Stylianos E. Orfanos

2nd Department of Critical Care, Attikon University Hospital

1 , Rimini Street

Haidari Athens 12462 (Greece)

E-Mail stylianosorfanosuoa@gmail.com 
predominant theory highlights repetitive alveolar injury, caused by a synergy of genetic predisposition and noxious environmental agents $[4,5]$. Repeated alveolar epithelial injury leads to apoptosis and hyperplasia [6], subsequent deregulation of epithelial-fibroblastic interactions and abnormal wound healing process [5]. Cell senescence is also affecting the repair process, as telomere premature shortening of type 2 alveolar epithelial cells was observed in IPF patients [7]. In IPF, resident fibroblasts differentiate into myofibroblasts under a profibrotic milieu, causing excessive extracellular matrix (ECM) deposition, fibroblast foci formation, and loss of alveolar function [3, 5]. Several patients succumb to an acute lung function decline, histologically and clinically akin to the acute respiratory distress syndrome, which is known as "acute exacerbation of IPF" [8].

Until the recent approval of pirfenidone and nintedanib $[9,10]$, there was no effective treatment for IPF, and agents that interact with fibroblasts have become of particular interest. Endothelin-1 (ET-1) is a potent vasoconstrictor and mitogenic agent with profibrotic properties. ET-1, a 21-amino acid peptide, along with ET-2 and ET-3, consists of the tree isoforms of the endothelin family [11]. ET-1 unfolds its actions through 2 receptors, ETA and ETB, producing opposite effects on the pulmonary circulation [11]. The endothelin system seems to participate in the pathogenesis of IPF $[12,13]$ by enhancing epithelialmesenchymal transition, fibroblast contractility, and collagen production, as documented by human and animal studies [14, 15]. Our group has demonstrated that ET-1 is also implicated in endothelial-mesenchymal transition in experimental pulmonary hypertension. [16] Furthermore, ET-1 modulates ECM synthesis and remodeling in dermal fibroblasts in vitro, with the degradation of ECM being ETA dependent [17], while transgenic overexpression of ET-1 in mice results in pulmonary fibrosis [18]. Nonselective inhibition of both ET-1 receptors, as well as moderately selective inhibition of ETA have been investigated in animal models of pulmonary fibrosis with promising results $[14,19]$; but related recent clinical trials were either harmful or ineffective [20]. However, the effect of highly selective ETA blockade in fibrosis models is so far unknown. We thus used sitaxentan, a highly selective, almost specific, ETA receptor antagonist (selectivity up to 6,500-fold) [11] in the bleomycin (BLM) mouse model. This animal model is widely used and is often regarded as the standard in modeling pulmonary fibrosis [21], since it reproduces its key features, including restrictive lung mechanics, epithelial cell injury, ECM deposition, and subpleural fibrosis [22]. The model comprises an initial in- flammatory stage (up to 14 days after BLM) followed by a fibrotic stage. In the present study, we showed that prophylactic highly selective ETA receptor antagonism can reduce the extent of inflammation and collagen deposition in the fibrotic mouse lung.

\section{Methods}

\section{Animals}

All experimentation was approved by the Ethics Committee of the Evangelismos Hospital Research Review Board (experimental study approval No. 141/2011), as well as by the Veterinary Service of the governmental prefecture of Attica, Greece (approval protocol No. K/1889/2011). The study was conducted in compliance with the EU Directive 2010/63/EU on animal experimentation. Animals were monitored daily and were randomly assigned into groups. All surgery was performed under deep anesthesia achieved by intraperitoneal administration of ketamine/xylazine (100 and $10 \mathrm{mg} / \mathrm{kg}$, respectively). All efforts were made to minimize animal distress and suffering. Euthanasia was performed under deep anesthesia by exsanguination.

Mice were bred and maintained on a C57BL/6 background in the animal facilities of the "Hellenic Pasteur Institute" (Athens, Greece) under specific pathogen-free conditions. Mice were then transported to the Animal Model Research Unit of Evangelismos Hospital, where they were housed at $20-22^{\circ} \mathrm{C}$, with $55 \pm 5 \% \mathrm{hu}-$ midity, and a 12-h light-dark cycle; food and water was given ad libitum during the experiment period.

In order to evaluate the possible pathological effects of sitaxentan in healthy animals, an initial group of mice was treated orally with sitaxentan for 21 days (sitaxentan; $15 \mathrm{mg} / \mathrm{kg} /$ day) dissolved in drinking $\mathrm{H}_{2} \mathrm{O}$. The control group $\left(\mathrm{H}_{2} \mathrm{O}\right)$ received only plain water for 21 days ( $n=3$ mice per group). The dose of sitaxentan used in these experiments was based on previous investigations [23].

\section{BLM Model}

Wild-type adult (8-10 weeks) male mice were subjected to BLM-induced lung injury. Intratracheal administration of $2 \mathrm{U} / \mathrm{kg}$ of BLM sulfate (Nippon Kayaku Co. Ltd) in $50 \mathrm{~mL}$ of sterile saline or saline alone was performed using an insulin syringe on an exposed trachea under intraperitoneal ketamine/xylazine anesthesia.

\section{Experimental Design}

The 4 experimental groups ( $n=5-11$ /group) were pretreated with either sitaxentan ( $15 \mathrm{mg} / \mathrm{kg} /$ day) or similar $\mathrm{H}_{2} \mathrm{O}$ volume into drinking water, starting at 1 day prior to either BLM or saline intratracheal injection (i.t.; day -1) and ending at the day of sacrifice, 7,14 , or 21 days after BLM or saline administration (day 0 ). The $\mathrm{SAL} / \mathrm{H}_{2} \mathrm{O}$ group was injected with saline i.t. at day 0 and received $\mathrm{H}_{2} \mathrm{O}$ for the study period. The BLM/ $\mathrm{H}_{2} \mathrm{O}$ group was injected with BLM sulfate i.t. at day 0 and received $\mathrm{H}_{2} \mathrm{O}$ for the study period. The SAL/SITAX group was treated with saline i.t. at day 0 , while the BLM/ SITAX group received BLM sulfate i.t. at day 0; both groups were drinking sitaxentan for the whole study period. In addition to the aforementioned preventive protocol, therapeutic administration of sitaxentan was also performed in the same, already described, experimental groups, starting 7 days after BLM or saline administration and ending on day 21 . 


\section{Lung Mechanics}

At 7, 14, and 21 days after BLM or saline administration, each animal was cannulated in order to obtain lung mechanics. The trachea was exposed under sterile conditions, while animals were under deep anesthesia by ketamine/xylazine (100 and $10 \mathrm{mg} / \mathrm{kg}$, respectively). A 22-gauge catheter was used for the cannulation of the trachea. Mechanical ventilation was performed using a small animal ventilator (Flexivent, Scireq, ON, Canada) and ambient air. Tidal volume $(\mathrm{Vt})$ was set at $8 \mathrm{~mL} / \mathrm{kg}$ while positive end-expiratory pressure was set at $2 \mathrm{~cm} \mathrm{H}_{2} \mathrm{O}$. A brief run-in period was followed by 2 deep inflations to total lung capacity for standardization purposes. After 1 min of Vt ventilation, measurements of lung function were obtained. Respiratory mechanics were evaluated by measuring tissue elastance coefficient $(\mathrm{H})$ via forced oscillation technique. This is achieved by the use of the constant phase model. The successive measurements were obtained in 30-s intervals. Following these maneuvers, 3 quasi-static pressure-volume curves were transduced in order to measure the static compliance (Cst) of the respiratory system by fitting the Salazar-Knowles equation to the expiratory branch of the PV loop [24].

\section{Samples}

At 7, 14, and 21 days after BLM or saline administration, lung mechanics evaluation was performed followed by blood collection, prior to animal sacrifice by exsanguination under deep anesthesia.

Venous blood samples were obtained from the abdominal inferior vena cava via heparinized 27-gauge syringe. Plasma samples were obtained via centrifugation of the blood samples at 1,500 rpm for $10 \mathrm{~min}$ at $4^{\circ} \mathrm{C}$ and stored at $-80^{\circ} \mathrm{C}$. Bronchoalveolar lavage fluid (BALF) was obtained via tracheotomy by injecting and slowly withdrawing $1 \mathrm{~mL}$ of phosphate-buffered saline (PBS). After repeating this procedure 3 times, the fluid was separated from cellular components by centrifugation at $1,500 \mathrm{rpm}$ for $10 \mathrm{~min}$ at $4^{\circ} \mathrm{C}$, and supernatants were stored at $-80^{\circ} \mathrm{C}$.

The lungs were exposed by a midthoracotomy incision, and the pulmonary arteries were perfused with PBS. The right lung was isolated with a ligature at the right hilum and was rinsed in PBS. The right lung was divided into 3 aliquots, each one of which was weighed, frozen in liquid nitrogen, and stored at $-80^{\circ} \mathrm{C}$ for further analysis. The left lung was inflated with $4 \%$ neutral-buffered paraformaldehyde instilled at $25 \mathrm{~cm} \mathrm{H}_{2} \mathrm{O}$ pressure through the trachea for $120 \mathrm{~min}$. The trachea was then tied and lung was immersed in $4 \%$ neutral buffered paraformaldehyde for $24 \mathrm{~h}$ before embedding in paraffin. From the animals used to examine the possible pathological effects of sitaxentan, liver, spleen, and kidney were also collected and immersed in $4 \%$ buffered paraformaldehyde for histopathological evaluation.

\section{BALF Total Protein, Total and Differential Cell Count}

Total protein concentration in the BALF was determined with the Bio-Rad Dc Protein Assay kit (Bio-Rad Laboratories, Hercules, CA, USA) according to the manufacturer's instructions.

Total cell counting in BALF was performed manually using an improved Neubauer hemocytometer according to common procedures. After the evaluation of total cell concentration in BALF, cells were removed via cytocentrifugation at $1,500 \mathrm{rpm}$ for $10 \mathrm{~min}$ and resuspended in PBS. Then, cytospins were prepared using a specific centrifuge (Cytospin3, Shandon) at a concentration of 50 to $70 \times 10^{3}$ cells per glass slide and let to air dry at room temperature for $12 \mathrm{~h}$. Each slide was stained per May-Grünwald-Giemsa according to standard procedures and viewed under a light microscope (Olympus BX50) to determine differential cell count.

\section{Biochemical Assays}

Levels of alanine aminotransferase, aspartate aminotransferase, and alkaline phosphatase in mouse plasma were measured by an autoanalyzer (ABX PENTRA 400; Horiba Ltd., Kyoto, Japan). Plasma was isolated from all 4 experimental groups 21 days after $\mathrm{BLM} /$ saline administration.

\section{Histological Lung Score}

Four-micrometer sections of paraffin-embedded tissues were stained with hematoxylin and eosin and graded for the presence and degree of lung injury by means of light microscopy. Features scored were focal thickening of alveolar membranes, congestion (distended blood vessels), interstitial and intra-alveolar neutrophil infiltration, and fibrosis. Each feature was assigned a score from 0 to 3 based on its absence " 0 " or presence to a mild " 1 ," moderate " 2 ," severe " 3 " degree, and a total cumulative histology score was determined, following the protocol by Murao et al. [25], with slight modifications. Scoring was performed by a pathologist blinded to treatment assignments.

\section{Soluble Collagen Evaluation}

Soluble collagen deposition in homogenized lung tissue from each animal was evaluated using a Sircol collagen assay kit (Sircol, Biocolor, Belfast, UK) specific for mammalian collagen types I to $\mathrm{V}$, according to manufacturer's protocol.

\section{Masson Trichrome Stain}

Collagen-specific stain was applied to $4-\mu \mathrm{m}$ sections of paraffin-embedded tissues via a Sigma Aldrich stain kit (HT15-1KT) according to manufacturer's protocol. Collagen is stained blue, while cytoplasm and muscle fibers are stained red allowing the optical observation of microscopic structure differences.

\section{Quantitative Real-Time Polymerase Chain Reaction}

Total RNA was isolated from mouse lungs 21 days after BLM/ saline administration using a PureLink RNA Mini kit (ThermoFisher Scientific, Waltham, MA, USA), followed by cDNA synthesis using a PrimeScript 1st strand cDNA Synthesis Kit (Takara Bio Inc., Shiga, Japan). PCR reaction mixtures were prepared using the KAPA SYBR Fast kit (Sigma-Aldrich), followed by quantitative

Fig. 1. Highly selective endothelin-1 receptor A inhibition does not affect tissue histology and does not induce mouse hepatotoxicity. a Total cell counts in bronchoalveolar lavage fluid (BALF) of mice receiving sitaxentan treatment $(15 \mathrm{mg} / \mathrm{kg} /$ day $)$ or $\mathrm{H}_{2} \mathrm{O}$ for 21 days. b Protein levels in BALF of the sitaxentan and control group. c Representative hematoxylin and eosin staining of 4- $\mu \mathrm{m}$ lung, liver, and kidney sections ( $n=3$ mice per group). d-f Plasma aspartate aminotransferase (AST), alanine aminotransferase (ALT), and alkaline phosphatase (AP) levels, respectively, in all groups of mice (including those treated with bleomycin [BLM]; $n=10$ per group). One-way ANOVA was followed by Tukey's multiple comparison test. Data are expressed as means \pm SEM.

(For figure see next page.) 


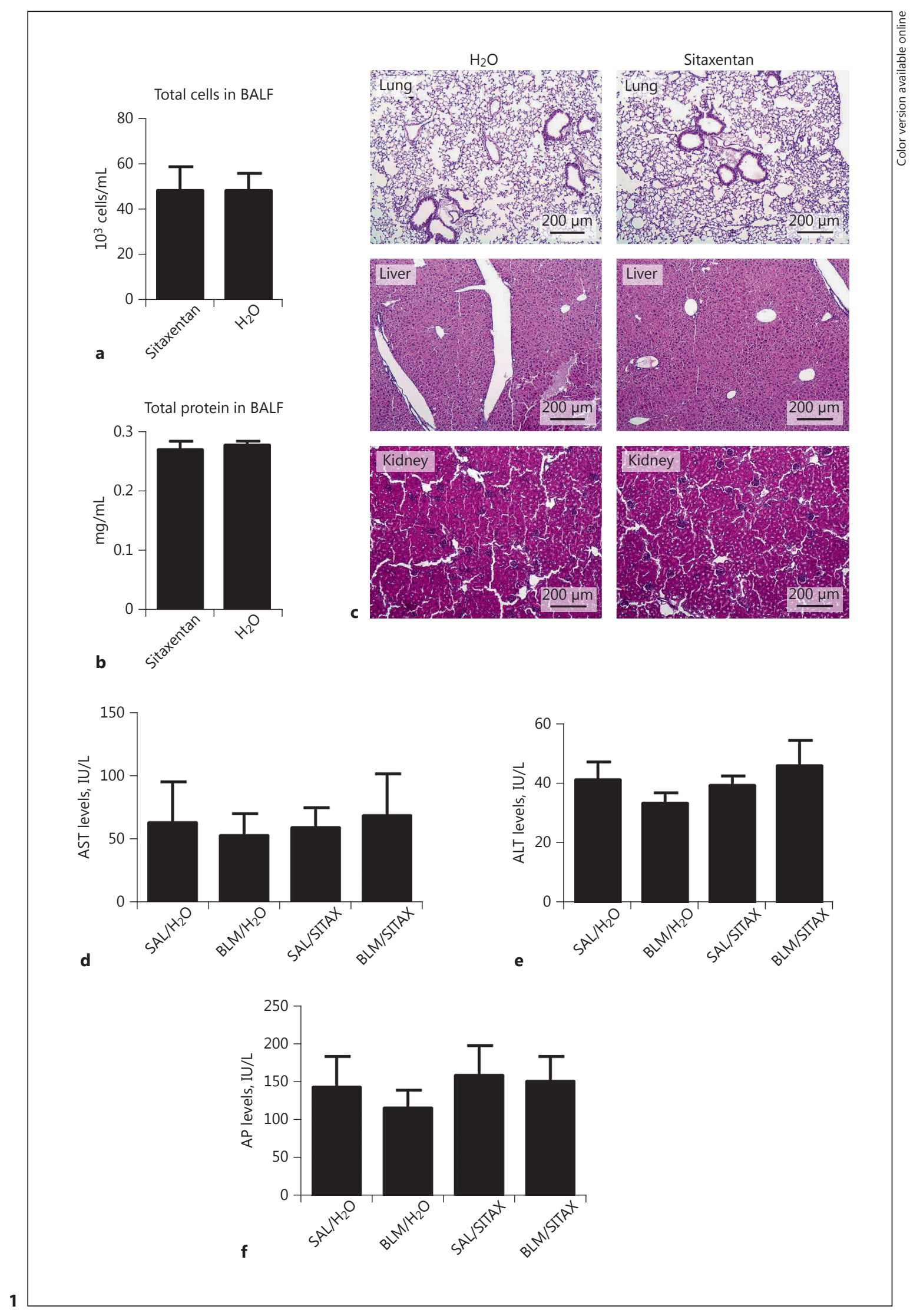


PCR on a CFX Connect Real time PCR detection system (Bio$\mathrm{Rad})$. The following primer pairs were used: ETA, 5'-ATCGGGATCCCCTTGATTAC-3' (forward) and $5^{\prime}$-ACAGCAACAGAGGCAGGACT-3' (reverse); ETB, 5'-TGTTCGTGCTAGGCATCATC-3' (forward) and $5^{\prime}$-AGCAATCTGCATACCGCTCT-3' (reverse); glyceraldehyde-3-phosphate dehydrogenase (GAPDH), 5'-AACTTTGGCATTGTGGAAGG-3' (forward) and 5'-ACACATTGGGGGTAGGAACA-3' (reverse). GAPDH served as the internal control to normalize the amount of loaded cDNA.

\section{Western Blotting}

SDS-PAGE was performed on $10 \%$ polyacrylamide gels, and samples were transferred to Immobilon-P PVDF membranes (Millipore, $0.45 \mu \mathrm{L}$ pore size; Millipore Corporation, Billerica, MA, USA). Membranes were probed with one of the following primary antibodies: phospho-focal adhesion kinase (p-FAK; US Biological, Swampscott, MA, USA), phospho-Akt, phospho-JNK, JNK, phospho-p44/42 MAPK, p44/42 MAPK, phospho-p38, p38 (Cell Signaling, Danvers, MA, USA), actin (Millipore, Temecula, CA, USA). Protein bands were detected by chemiluminescence (PerkinElmer Inc., Waltham, MA, USA). For quantification, densitometric analysis was performed and the expression level of each protein was normalized to actin.

\section{Statistical Analysis}

Data are presented as means \pm SEM and as medians with interquartile range. Comparisons among groups were made using oneway randomized ANOVA, followed by Dunnett's, post hoc test, with the SAL $/ \mathrm{H}_{2} \mathrm{O}$ group serving as control (significant differences shown by ${ }^{*}$ ). Significant differences between the $\mathrm{BLM} / \mathrm{H}_{2} \mathrm{O}$ and BLM/SITAX groups were tested by Newman-Keuls' or Tukey's multiple comparison tests, as appropriate (shown as \#). Two-way ANOVA was followed by Bonferroni multiple comparisons test and was used to show differences among groups on the soluble collagen assay; differences between $\mathrm{BLM} / \mathrm{H}_{2} \mathrm{O}$ group and $\mathrm{SAL} / \mathrm{H}_{2} \mathrm{O}$ or SAL/SITAX groups are shown by *; differences between BLM/ $\mathrm{H}_{2} \mathrm{O}$ group and BLM/SITAX group are shown by \#. Groups in the survival curve were compared using the log rank test; differences among groups are presented as *. Survival probabilities by time were estimated and shown graphically using the Kaplan-Meier method. Statistical analyses were conducted with the statistical program Graph Pad Prism vol. 5 (Graph Pad Software Inc., CA, USA). All $p$ values are two-sided. Statistical differences are considered significant when $p<0.05$.

\section{Results}

\section{Effects of Sitaxentan Administration on Organ}

Histopathology and Hepatotoxicity

As ET-1 inhibition through selective or mixed receptor blockade has been previously linked with hepatic toxicity in humans [26-28], we investigated the potential adverse effects of sitaxentan in healthy mice by administering the drug at the dose used for the BLM experiment for 21 days. None of the experimental groups (Sitaxentan or $\mathrm{H}_{2} \mathrm{O}$ ) showed alveolar space inflammation as evidenced by BALF pleocytosis (Fig. 1a), or increased protein levels (Fig. 1b). Moreover, histological evaluation of lung, liver, and renal tissue samples from both groups by light microscopy revealed no abnormality (Fig. 1c). Emphasis was given particularly on liver toxicity, and for that reason plasma samples were obtained from all 4 groups of mice used in the prophylactic experiment, and levels of alanine aminotransferase, aspartate aminotransferase, and alkaline phosphatase were measured (Fig. 1d-f). None of the hepatotoxicity markers showed significant differences among groups.

\section{Highly Selective ETA Receptor Prophylactic Inhibition}

Improves Survival and Lung Function in the BLM

Animal Model

The BLM mouse model is characterized by increased mortality [29]. Although our work was not designed as a mortality study, we noted that BLM administration resulted in a cumulative mortality of $40 \%$ at day 21 . The majority of animals died between days 10 and 16 when the fibrotic phase followed a fully developed inflammation. Interestingly, sitaxentan treatment totally reversed the phenomenon (Fig. 2) as no mortality was observed in the BLM group treated with sitaxentan.

Increased work of breathing due to pulmonary edema or fibrosis leads to respiratory failure, and preservation of lung function is a major prerequisite of any treatment of lung disease. To assess the effect of BLM on respiratory mechanics, we measured quasi-static respiratory system compliance (Cst) via pressure-volume curves as well as lung tissue elastance $(\mathrm{H})$ by the forced oscillation technique, both methods shown to accurately reflect lung function alterations in the BLM model [24]. BLM tracheal instillation resulted in increased $\mathrm{H}$ and decreased Cst of BLM/ $\mathrm{H}_{2} \mathrm{O}$ group at 7, 14, and 21 days after BLM compared to the $\mathrm{SAL} / \mathrm{H}_{2} \mathrm{O}$ group (Fig. 3a-f); most notably at day 21 due to the evolution of full-blown fibrosis, and this was partially mitigated by sitaxentan $(p<$ 0.001 ). At the earlier time points, sitaxentan appeared to mostly counteract the restrictive phenotype induced by BLM.

\section{Highly Selective ETA Receptor Inhibition Prevents \\ BLM-Induced Lung Pathology}

Acute lung injury by BLM was visible on day 7, but scores reached statistical significance at days 14 and 21 . Representative lung histology revealed that even from day 7 , alveolar thickening, massive infiltration of leukocytes, and distorted lung architecture were present (Fig. $4 a-c)$. At later states, accumulation of fibrous tissue 


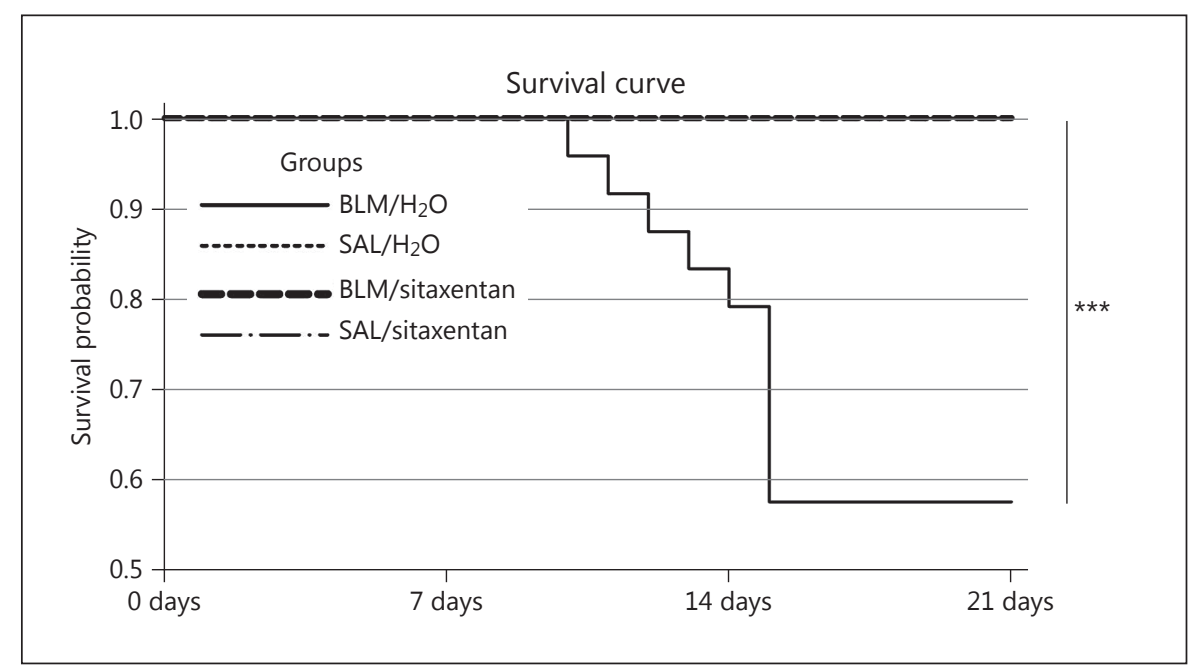

Fig. 2. Highly selective prophylactic endothelin-1 receptor A (ETA) receptor inhibition improves survival of bleomycin-challenged mice. Effect of highly selective ETA inhibition by means of sitaxentan treatment $(15 \mathrm{mg} / \mathrm{kg} /$ day $)$ on mortality due to bleomycin (BLM) challenge. The SAL/ $\mathrm{H}_{2} \mathrm{O}$ group was treated with saline at day 0 and received $\mathrm{H}_{2} \mathrm{O}$ for the period needed. The $\mathrm{BLM} / \mathrm{H}_{2} \mathrm{O}$ group received BLM sulfate at day 0 and received $\mathrm{H}_{2} \mathrm{O}$ for the period needed. The SAL/sitaxentan group was treated with saline at day 0 and was drinking sitaxentan for the period needed. The $\mathrm{BLM} /$ sitaxentan group received BLM sulfate at day 0 and was drinking sitaxentan for the period needed. Sitaxentan treatment started at day -1 and continued throughout the experimental procedure. Comparison of Kaplan-Meier survival curves among the 4 experimental groups. BLM instillation ( $\mathrm{BLM} / \mathrm{H}_{2} \mathrm{O}$ group) caused a mortality rate of $40 \%$ until day 21 , while sitaxentan administration starting 1 day prior to BLM completely reversed the phenomenon. Groups were compared using the log rank test. The curves of the 3 groups $\mathrm{SAL} / \mathrm{H}_{2} \mathrm{O}, \mathrm{SAL} /$ sitaxentan, $\mathrm{BLM}$ /sitaxentan show a complete overlap (100\% survival, no deaths were observed). *** $p<0.001, \mathrm{BLM} / \mathrm{H}_{2} \mathrm{O}$ vs. BLM/sitaxentan. predominates. Highly selective ETA receptor inhibition alleviated microstructural lung alterations (Fig. 4d-f).

Highly Selective ETA Receptor Prophylactic Inhibition Reduces Airspace Inflammation in the BLM Mouse Model

The lung's acute response to BLM features a macrophage and neutrophil-dominated inflammatory response followed by microvascular discontinuity resulting in leakage of fluid and macromolecules in the airspace [24]. For quantification, we measured BALF total cell content and found increased numbers at all time points in response to BLM (Fig. 5a-c). Cell accumulation peaked at day 7 (Fig. 5a) and remained elevated throughout the experiment, with an only slight downward trend. Differential cell count revealed macrophages as the predominant cell type (Fig. 5d-f). Highly selective prophylactic ETA receptor inhibition attenuated cell infiltration (total and both subtypes) in BALF at all 3 time points. BLM additionally caused increased protein concentration in BALF at all time points. Interestingly, sitaxentan did not seem to prevent this from rising until the final time point at day 21 (Fig. 5j-1).

ETA Receptor Inhibition in

Bleomycin-Induced Fibrosis

\section{Highly Selective ETA Receptor Prophylactic Inhibition}

Decreases Lung Collagen Deposition

The inflammatory phase of the BLM model is anteceded by a fibrotic phenotype characterized by massive collagen deposition, mainly due to collagen-producing myofibroblasts [21]. Fibrosis was evaluated by determining soluble collagen concentration at every time point. BLM instillation caused increased collagen expression at day 21 and highly selective ETA receptor inhibition attenuated this increase (Fig. 6a). Specific collagen Masson trichrome staining revealed extensive collagen deposits at day 21 (Fig. 6b), leading to profound alveolar structure distortion. Prophylactic treatment with sitaxentan was associated with significantly less collagen deposition as measured by soluble collagen level and showed by collagen staining (Fig. 6b; BLM/SITAX).

Sitaxentan administration prevented the development of BLM-induced pulmonary inflammation and fibrosis, suggesting a likely involvement of ET-1 signaling in the pathogenesis of the modelled disease. However, administration of the compound starting at day 7 after BLM administration had no statistically significant effects (online suppl. Fig. 1; for all online suppl. material, see www. karger.com/doi/10.1159/000481201). 


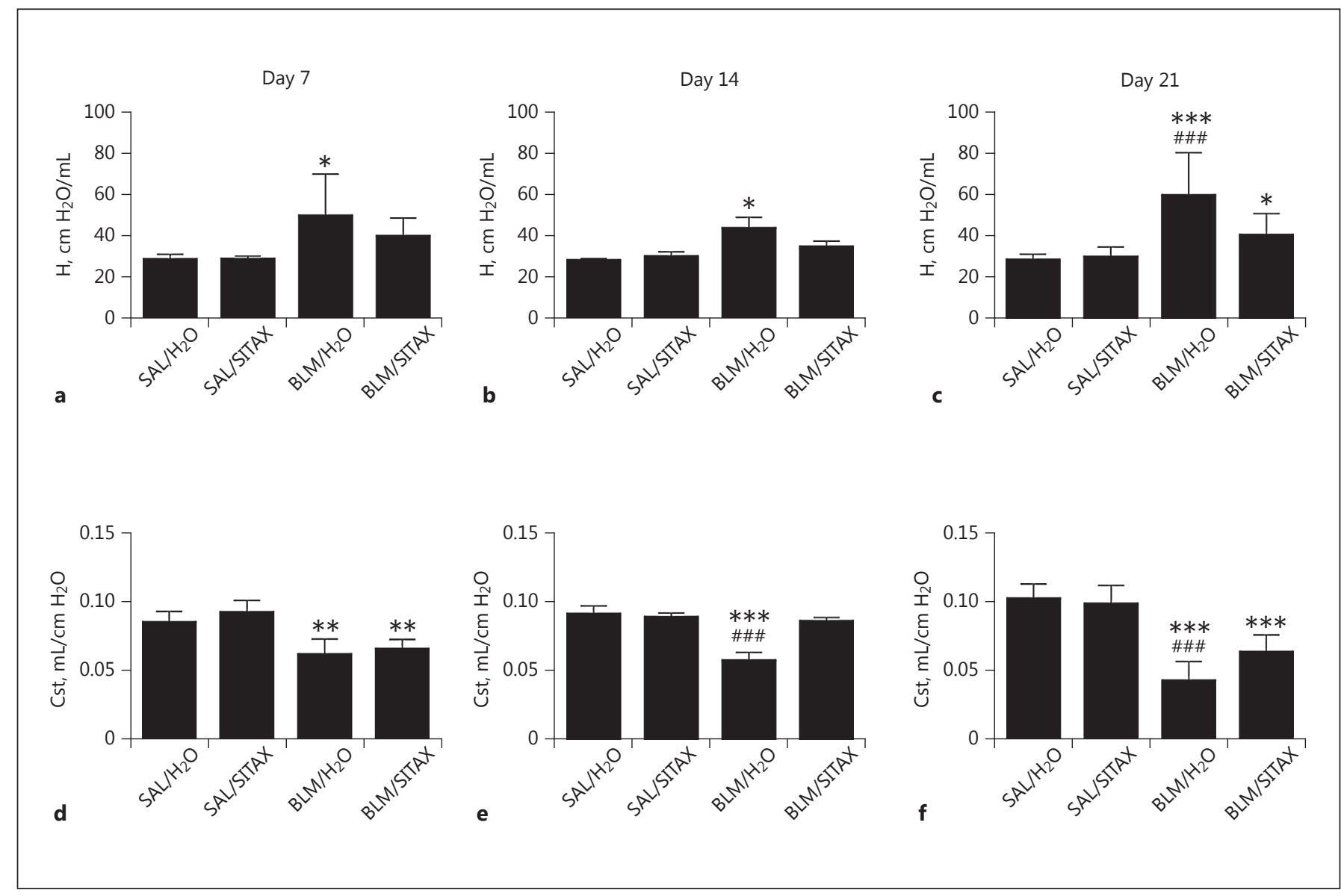

Fig. 3. Evaluation of lung mechanics in all animal groups at different time points. BLM administration led to increased tissue elastance $(\mathrm{H})(\mathbf{a}-\mathbf{c})$ and decreased static compliance (Cst) (d-f). Oneway ANOVA followed by Dunnett's post hoc test was used for the comparison between $\mathrm{SAL} / \mathrm{H}_{2} \mathrm{O}$ (served as control group) and each of the other 3 groups (SAL/SITAX, BLM/ $\mathrm{H}_{2} \mathrm{O}$, and BLM/SITAX; differences shown by*). Additionally, one-way ANOVA followed by the Newman-Keuls post hoc test was used for the comparison between the $\mathrm{BLM} / \mathrm{H}_{2} \mathrm{O}$ and the BLM/SITAX groups (differences shown by \#). Sitaxentan treatment $(15 \mathrm{mg} / \mathrm{kg} /$ day) throughout the experimental procedure, starting 1 day prior to BLM, resulted in improved elastance at day 21 (c) as well as static compliance $(\mathbf{e}, \mathbf{f})$. $n=5-11$ /group. Data are expressed as means \pm SEM. ${ }^{*} p<0.05$; ${ }^{* *} p<0.01 ;{ }^{* * *} p<0.001 ;{ }^{\# \# \#} p<0.001$. Other abbreviations as per legend of Figure 2.

\section{Mechanistic Insights into ET-1 Inhibition Signaling}

In order to find whether sitaxentan pretreatment modifies the expression of ET-1 downstream targets, the expression of ET-1 receptors was first studied; no major effect in their expression was observed (online suppl. Fig. 2). Since focal adhesion kinase (FAK) and PI3-kinase/Akt are critical regulators of profibrotic signaling pathways [30-34], we then explored the involvement of these pathways in our preventive administration model. BLM increased the activity of both pathways at the 21-day time point (Fig. 7a, b), but only FAK activation depended on ETA receptor, since its phosphorylation was decreased
Fig. 4. Highly selective ETA receptor prophylactic inhibition attenuates bleomycin-induced lung injury. a-c Representative hematoxylin and eosin (H\&E) stainings of 4- $\mu \mathrm{m}$ mouse lung sections. Lung samples were received from all 3 time points, 7,14 , and 21 days after BLM or saline, of all 4 groups $\left(\mathrm{SAL} / \mathrm{H}_{2} \mathrm{O}, \mathrm{SAL} / \mathrm{SITAX}\right.$, $\mathrm{BLM} / \mathrm{H}_{2} \mathrm{O}, \mathrm{BLM} / \mathrm{SITAX}$ ). BLM induced infiltration of leukocytes $(\mathbf{a}, \mathbf{b})$, alveolar thickening $(\mathbf{a}-\mathbf{c})$, and collagen deposition $(\mathbf{b}, \mathbf{c})$ in the lung. $\mathbf{d}$-f Quantification of lung injury was performed using 4- $\mu \mathrm{m}, \mathrm{H} \& \mathrm{E}-\mathrm{stained}$, mouse lung sections of all animals included in each group at every time point, 7, 14, and 21 days after BLM, respectively. One-way ANOVA was used for comparison among groups (see Fig. 3 legend). $n=5-11$ /group. Data are expressed as means \pm SEM. ${ }^{*} p<0.05$; $^{* * *} p<0.001$; $^{\# \#} p<0.001$. Other abbreviations as per legend of Figure 2.

(For figure see next page.) 


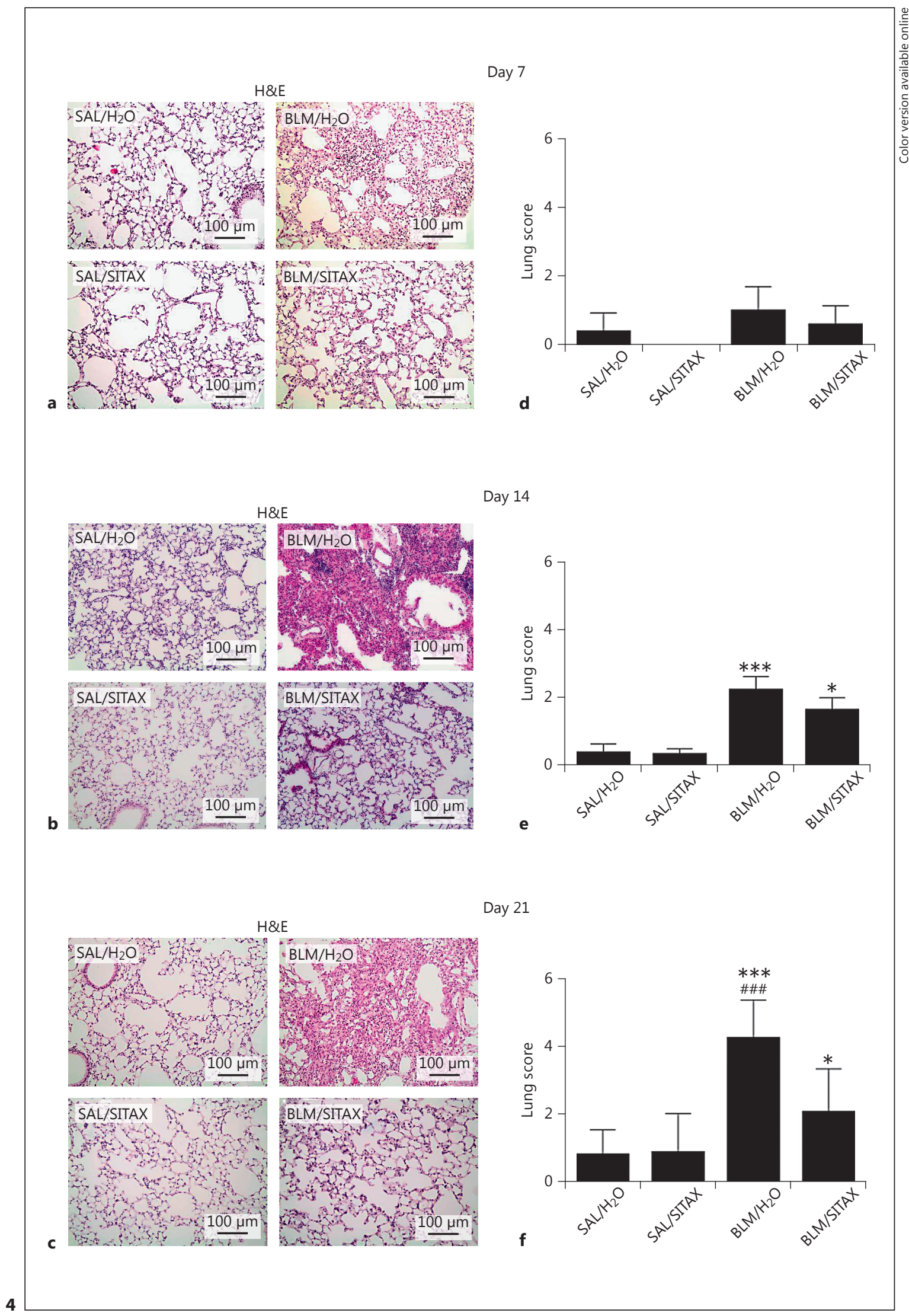


in sitaxentan-treated mice. Conversely, the PI3/Akt pathway was also activated by BLM but in a manner independent of ETA signaling (Fig. 7c, d).

In order to reveal other downstream targets of the ET-1 pathway involved, we investigated the mitogen-activated protein kinase (MAPK) signaling pathways. Western blot analysis with anti-phospho-JNK, anti-phosphop38, and anti-phospho-ERK revealed that these pathways are activated upon BLM challenge (Fig. 7e-j). JNK phosphorylation decreases in tissues from mice pretreated with sitaxentan (Fig. 7e, f). Pretreatment with sitaxentan was also shown to reduce BLM-induced $\mathrm{p} 38$ phosphorylation in mouse lungs (Fig. 7g, h). Finally, Western blots performed revealed the involvement of the $\mathrm{p} 42 / 44$ signaling mechanism in sitaxentan-mediated effects, as sitaxentan-pretreated mice having received BLM showed an amelioration in p42/44 activation (Fig. 7i, j).

\section{Discussion}

Prior work has shown increased secretion of endothelins in IPF leading to paracrine receptor activation and, presumably, sustaining the fibrotic process. Since many fibrotic features appear to be promoted by ETA receptors $[33,35,36]$, we tested the effect of highly selective ETA receptor blockade in BLM-induced murine lung inflammation and fibrosis. Although nonselective ET-1 receptor inhibition improves the BLM lesion in rodents, there is a theoretical advantage to preserving ETB receptor signaling [11-13], since endothelial ETB receptor promotes vasodilatory and anti-inflammatory actions and clears ET-1 from the pulmonary circulation [37, 38]. Despite encouraging preclinical results, however, several randomized control trials using nonselective or modestly selective ETA receptor antagonists in IPF patients showed no benefit [39-42]. Thus, the aim of this study was to delineate the role of highly selective ETA receptor inhibition in pulmonary fibrosis using the BLM mouse model. This model reproduces key features of the human disease, such as altered lung mechanics, ECM deposition, fibroblast/ myofibroblast accumulation and subpleural fibrosis. Despite limitations [43], such as the absence of hyperplastic type II alveolar epithelial cells and the occasional latestage spontaneous resolution of fibrosis [21], the model remains the best characterized and most widely used experimental model of IPF.

To block ETA, we administered sitaxentan, which inhibits the ETA receptor up to 6,500 times more selectively than the ETB receptor [11]. Although this drug has been associated with hepatic toxicity [26-28], we observed no obvious lung, liver, or kidney pathology. Even more, we observed no elevated blood aminotransferase, or alkaline phosphatase levels indicative of hepatotoxicity, in all experimental groups (including the animals which received BLM) for the duration of the study. However, we cannot exclude adverse effects of longer administrations, as shown in humans.

Mortality due to BLM is dose-dependent $[29,44]$ and reached $40 \%$ in our experiment but was entirely prevented by highly selective ETA receptor inhibition. The majority of deaths occurred within the 10th and 16th day time period of BLM exposure; therefore, the positive effect of sitaxentan on mortality is mostly attributable to attenuated acute lung injury, given that ET-1 reportedly mediates acute lung injury via several epithelial and endothelial mechanisms [45]. Restrictive lung mechanical alterations by BLM commence during the inflammation stage, most likely due to edema formation, and progress into the fibrotic stage [24] due to bronchial wall thickening, and collagen deposition. Highly selective ETA prophylactic inhibition by sitaxentan improved to a large extent lung function at all time points, suggesting that ETA is involved in promoting both the acute inflammatory and the chronic fibrotic effect of BLM. Of note, although sitaxentan prevented BALF pleocytosis starting early (day 7) and lasting for the whole experimental duration, it attenuated the increased protein BALF content at a later stage (day 21), denoting different effects on the related inflammatory pathways with ETA receptor blockade affecting the latter at the fibrotic stage.

The lung's initial response to BLM is characterized by neutrophilic and lymphocytic pan-alveolitis within the first days [21], in association with production of free radicals, proinflammatory cytokines, and leukocyte activation [22]. The observed leukocytic pan-alveolitis in our model was suppressed to a large extent by highly selective ETA inhibition, following preventive sitaxentan administration, thus highlighting the role of ETA in driving inflammation. This is in apparent contrast with sitaxentan's inefficacy in a rat model of lipopolysaccharide (LPS) administration, which may be explained by the acute (LPS) versus subacute (BLM) time-course of the models [46]. Furthermore, in agreement with our findings, Hocher et al. [18] showed that ET-1 overexpression in the lungs of transgenic mice was related to inflammatory cell recruitment (mainly mononuclear cells) around pulmonary arteries, and was associated with pulmonary fibrosis development. 


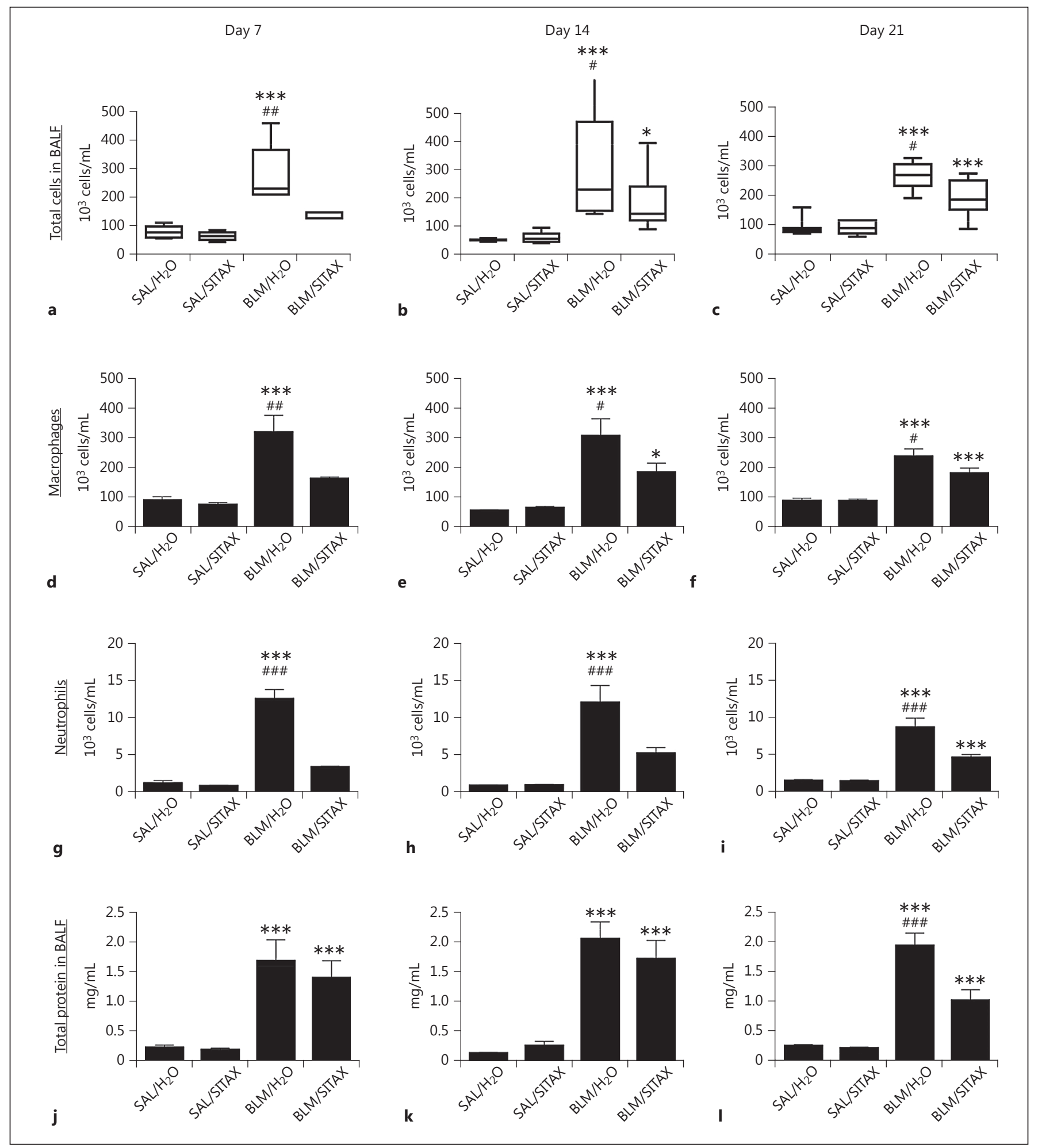

Fig. 5. Effects of highly selective ETA receptor prophylactic inhibition on cell infiltration in bronchoalveolar lavage fluid. a-c Total cell counts. d-f Macrophage counts. g-i Neutrophil counts. j-I Protein concentrations in BALF. Samples were collected at days 7, 14 , and 21, respectively. One-way ANOVA was used for compari- son among groups (see Fig. 3 legend) $n=5-11$ /group. Data are expressed as means \pm SEM or boxplots (line in the box: median value; box edges: $25-75$ th centiles; whiskers: range of values). ${ }^{*} p<0.05 ;{ }^{\#} p<0.05 ;{ }^{\# \#} p<0.01 ;{ }^{* * *} p<0.001 ;{ }^{\# \#} p<0.001$. Other abbreviations as per legend of Figure 2 .
ETA Receptor Inhibition in Bleomycin-Induced Fibrosis
Respiration 2018;95:122-136 DOI: $10.1159 / 000481201$ 
Fig. 6. Highly selective ETA receptor prophylactic inhibition attenuates collagen deposition in bleomycin-challenged mouse lungs. a Soluble collagen determination in lung extracts as measured by Sircol collagen kit. Data are presented as boxplots (line in the box: median value; box edges: 25 th to 75th centiles; whiskers: range of values). b Representative Masson staining of $4-\mu \mathrm{m}$ lung sections from samples collected at day 21. Two-way ANOVA followed by Bonferroni multiple comparisons test was used to compare each group with all the others for each time point. Differences between the $\mathrm{BLM} / \mathrm{H}_{2} \mathrm{O}$ and the $\mathrm{SAL} / \mathrm{H}_{2} \mathrm{O}$ or SAL/SITAX group are shown by *. Differences between the $\mathrm{BLM} / \mathrm{H}_{2} \mathrm{O}$ and the BLM/SITAX group are shown by \#. The symbols (* or \#) that are used in Figure $6 \mathrm{~A}$ refer to time point of day $21 .{ }^{* * *} p<0.001 ;^{\# \# \#} p<0.001$. $n=5-11$ /group. Other abbreviations as per legend of Figure 2.
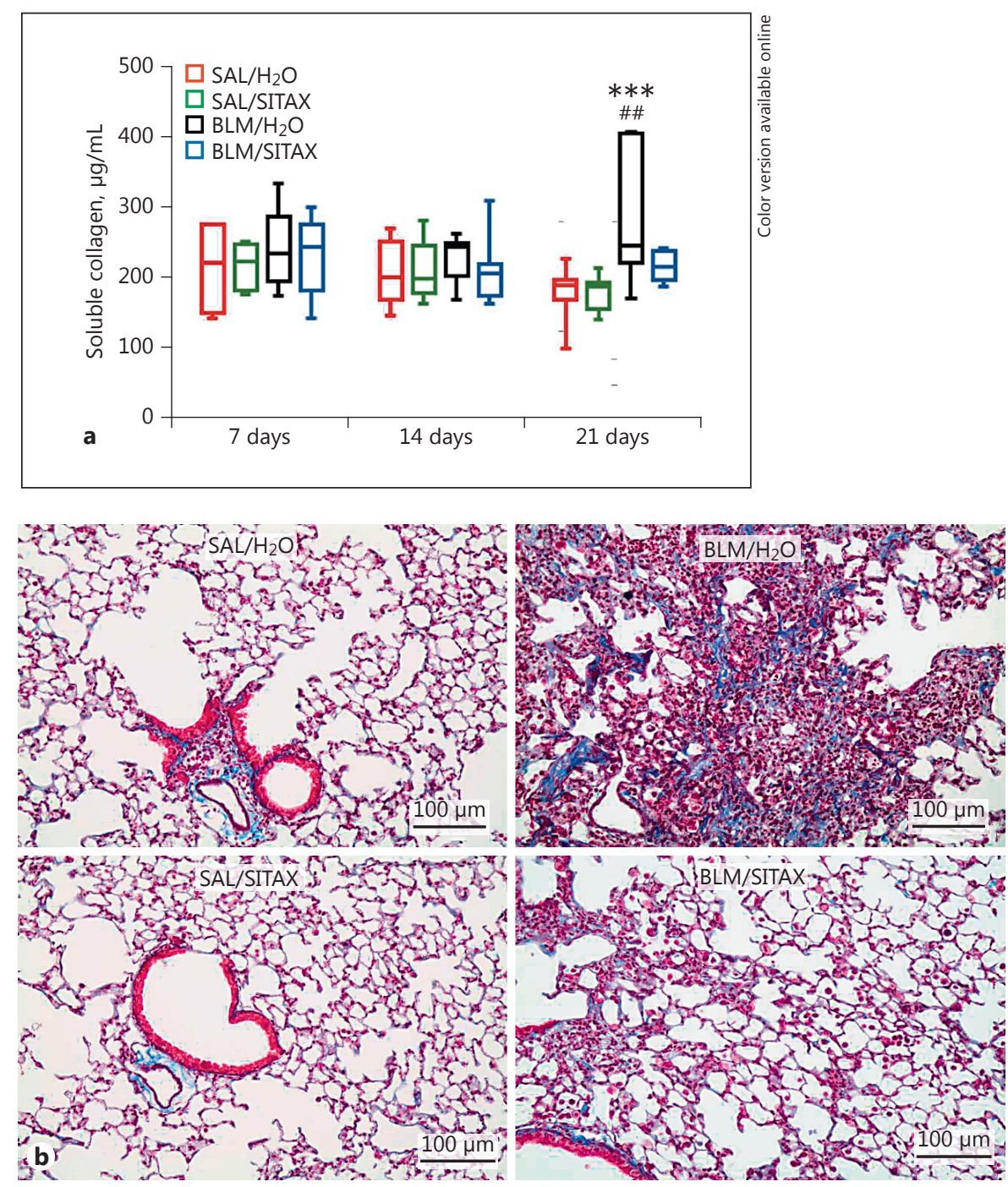

Endothelin-1 facilitates capillary fluid leakage and edema formation via the ETA receptor and vascular endothelial growth factor in the presence of inflammatory cells [47-49]; Additionally, ETB receptor deficiency is related to vascular leak under normoxia, while hypoxia further exacerbates the process [48]. The aforementioned data support that our sitaxentan-related findings may be initially due to the anti-inflammatory role of highly selective ETA receptor blockade and the vasoprotective effects exhibited by the free and functional ETB receptors; this early beneficial effect appears extended in the fibrotic stage of the BLM model. A limitation of our study is the lack of a second model proving antifibrotic efficacy, such as the CC10-driven, tetracycline-controlled transgenic
Fig. 7. Highly selective ETA receptor prophylactic inhibition reduces phosphorylation of FAK and MAPKs. a, c Representative Western blots for p-FAK and p-Akt, respectively, in mouse lung homogenates of samples collected 21 days after BLM challenge or vehicle. Actin was used as loading control. $\mathbf{b}, \mathbf{d}$ Quantification of protein levels shown in $\mathbf{a}$ and $\mathbf{c}$ after normalization to actin. $\mathbf{e}, \mathbf{g}, \mathbf{i}$ Representative tissue lysate immunoblot analyses with anti-phospho-JNK, anti-phospho-p38, and anti-phospho p42/44 antibodies, respectively, 21 days after BLM or vehicle. Total contents of JNK, p38, and p42/44 were used as loading controls. f, h, j Quantification of protein levels shown in $\mathbf{e , ~} \mathbf{g}$, i. One-way ANOVA was used for comparison among groups, and was followed by Tukey's multiple comparisons test. Data are expressed as means \pm SEM. Differences between the $\mathrm{BLM} / \mathrm{H}_{2} \mathrm{O}$ and $\mathrm{SAL} / \mathrm{H} 2 \mathrm{O}$ groups are shown by *; differences between the BLM/ $\mathrm{H}_{2} \mathrm{O}$ and BLM/SITAX groups are shown by \#. ${ }^{*} p<0.05{ }^{\#} p<0.05 ;{ }^{* *} p<0.01$.

(For figure see next page.) 


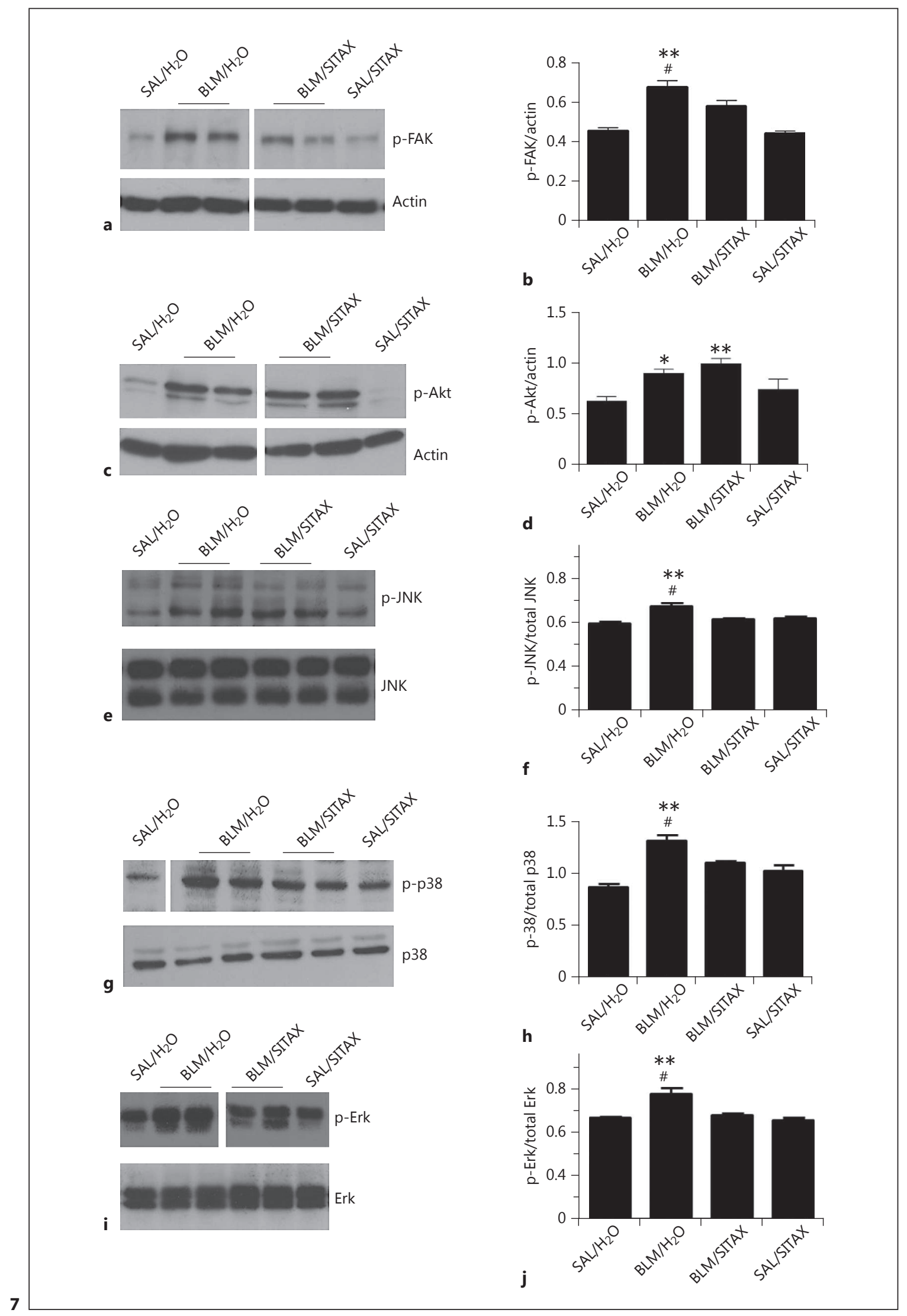


system, adenoviral transforming growth factor- $\beta$ (TGF- $\beta$ ) overexpression or silica-induced fibrosis $[50,51]$. Despite that, we showed that highly selective preventive ETA receptor repression decreased collagen deposition and aborted the remodeling process.

However, therapeutic administration of sitaxentan beginning on day 7 after BLM had no significant effects, denoting that in our model highly selective ETA inhibition prevents the BLM-induced pathological process but does not appear to reverse this process once started. These findings limit the possible applicability of the used compound to the human fibrotic disease, adding to the severe hepatotoxicity already observed in humans with pulmonary arterial hypertension. The purpose of this investigation, however, was to study highly selective ETA inhibition in BLM-induced fibrosis, and not to explore potential clinical applicability.

We next sought to investigate possible molecular signaling mechanisms underlying the protective effect of highly selective ETA blockade. The expression levels of ETA and ETB receptors among groups was first studied but was not found to be affected by sitaxentan administration. We then focused on pathways previously proposed to participate in pulmonary fibrosis including FAK and PI3/Akt cascade [12]. Activation of the FAKintegrin axis by the adhesion of fibroblasts to matrix leads to the induction of profibrotic gene expression [52]. In this context, FAK has been shown to be a critical factor in signaling pathways induced by profibrotic agents such as connective tissue growth factor, TGF- $\beta$, and ET-1 [53-55]. More specifically, ET-1 time- and dose-dependently promotes FAK activation (phosphorylation) in fibroblasts and induces FAK-dependent expression of both collagen type I and $\alpha$-SMA [54], in addition to enhancing the adhesive capacity of fibrotic cells [30]. Chemical or genetic ablation of FAK decreased BLM-induced fibrosis in mice but had no impact on early inflammation and vascular leakage [54]. In accordance with the above, we observed an increase in activated FAK in the fibrotic lungs of our model at day 21 , which was attenuated by prophylactic sitaxentan treatment. This suggests that by reducing the amount of activated FAK, highly selective ETA receptor blockade may mediate an antifibrotic phenotype [52-55].

In contrast, we did not find a difference in the activation status of the PI3/Akt pathway, which did not respond to selective ETA receptor blockade; this may be related to Akt activation by alternate pathways, probably TGF- $\beta$ [32] that is known to interact with ET-1 in the regulation of fibrotic responses [12]. MAPK signaling pathways

studied here were also found to be implicated in the protective effect of highly selective ETA blockade. Sitaxentan effects were shown to be mediated by ERK, p38 and JNK signaling mechanisms, as pretreatment with sitaxentan affected the degree of their phosphorylation in mouse lung extracts. Our results are in agreement with published data showing that ET-1 induces fibrosis in lung fibroblasts in a MAPK-dependent manner [33]. Besides, a large amount of literature already supports a role of JNK in collagen deposition and fibrosis [56] as well as the involvement of the p38 pathway in pulmonary fibrosis mechanisms [57].

\section{Conclusions}

We have demonstrated that daily administration of the highly selective ETA inhibitor sitaxentan for 22 days starting 1 day prior to BLM challenge is well tolerated by healthy and BLM-exposed mice and significantly attenuates lung dysfunction, inflammation, and fibrosis and improves survival. These results underscore the role of ETA as a potent regulator in lung inflammation and repair.

\section{Acknowledgements}

The authors would like to thank Pfizer Hellas for the unrestricted Investigator Initiated Research grant (grant No.: WS982787) as well as Mrs. Zoe Kollia for her excellent technical assistance.

References

Respiration 2018;95:122-136 DOI: $10.1159 / 000481201$
1 Kekevian A, Gershwin ME, Chang C: Diagnosis and classification of idiopathic pulmonary fibrosis. Autoimmun Rev 2014;13:508-512.

2 Camelo A, Dunmore R, Sleeman MA, Clarke DL: The epithelium in idiopathic pulmonary fibrosis: breaking the barrier. Front Pharmacol 2014;4:173.

3 Woodcock HV, Maher TM: The treatment of idiopathic pulmonary fibrosis. F1000Prime Rep 2014;6:16.

4 Richeldi L, Collard HR, Jones MG: Idiopathic pulmonary fibrosis. Lancet 2017;389:19411952.

5 Wuyts WA, Agostini C, Antoniou KM, Bouros D, Chambers RC, Cottin V, Egan JJ, Lambrecht BN, Lories R, Parfrey $\mathrm{H}$, et al: The pathogenesis of pulmonary fibrosis: a moving target. Eur Respir J 2013;41:1207-1218.

6 Borensztajn K, Crestani B, Kolb M: Idiopathic pulmonary fibrosis: from epithelial injury to biomarkers - insights from the bench side. Respiration 2013;86:441-452. 
7 Magnini D, Montemurro G, Iovene B, Tagliaboschi L, Gerardi RE, Lo Greco E, Bruni T, Fabbrizzi A, Lombardi F, Richeldi L: Idiopathic pulmonary fibrosis: molecular endotypes of fibrosis stratifying existing and emerging therapies. Respiration 2017;93: 379-395.

8 Juarez MM, Chan AL, Norris AG, Morrissey BM, Albertson TE: Acute exacerbation of idiopathic pulmonary fibrosis - a review of current and novel pharmacotherapies. J Thorac Dis 2015;7:499-519.

9 King TE Jr, Bradford WZ, Castro-Bernardini S, Fagan EA, Glaspole I, Glassberg MK, Gorina E, Hopkins PM, Kardatzke D, Lancaster $L$, et al: A phase 3 trial of pirfenidone in patients with idiopathic pulmonary fibrosis. $\mathrm{N}$ Engl J Med 2014;370:2083-2092.

10 Richeldi L, du Bois RM, Raghu G, Azuma A, Brown KK, Costabel U, Cottin V, Flaherty KR, Hansell DM, Inoue Y, et al: Efficacy and safety of nintedanib in idiopathic pulmonary fibrosis. N Engl J Med 2014;370:2071-2082.

11 Vachiery JL, Davenport A: The endothelin system in pulmonary and renal vasculopathy: les liaisons dangereuses. Eur Respir Rev 2009; 18:260-271.

12 Fonseca C, Abraham D, Renzoni EA: Endothelin in pulmonary fibrosis. Am J Respir Cell Mol Biol 2011;44:1-10.

13 Swigris JJ, Brown KK: The role of endothelin-1 in the pathogenesis of idiopathic pulmonary fibrosis. Biodrugs 2010;24:49-54.

14 Park SH, Saleh D, Giaid A, Michel RP: Increased endothelin-1 in bleomycin-induced pulmonary fibrosis and the effect of an endothelin receptor antagonist. Am J Respir Crit Care Med 1997;156:600-608.

15 Reichenberger F, Schauer J, Kellner K, Sack U, Stiehl P, Winkler J: Different expression of endothelin in the bronchoalveolar lavage in patients with pulmonary diseases. Lung 2001; 179:163-174.

16 Nikitopoulou I, Orfanos SE, Kotanidou A, Maltabe V, Manitsopoulos N, Karras P, Kouklis P, Armaganidis A, Maniatis NA: Vascular endothelial-cadherin downregulation as a feature of endothelial transdifferentiation in monocrotaline-induced pulmonary hypertension. Am J Physiol Lung Cell Mol Physiol 2016;311:L352-L363.

17 Shi-Wen X, Denton CP, Dashwood MR, Holmes AM, Bou-Gharios G, Pearson JD, Black CM, Abraham DJ: Fibroblast matrix gene expression and connective tissue remodeling: role of endothelin-1. J Invest Dermatol 2001;116:417-425.

18 Hocher B, Schwarz A, Fagan KA, ThoneReineke C, El-Hag K, Kusserow H, Elitok S, Bauer C, Neumayer HH, Rodman DM, et al: Pulmonary fibrosis and chronic lung inflammation in ET-1 transgenic mice. Am J Respir Cell Mol Biol 2000;23:19-26.
19 Schroll S, Arzt M, Sebah D, Nuchterlein M, Blumberg F, Pfeifer M: Improvement of bleomycin-induced pulmonary hypertension and pulmonary fibrosis by the endothelin receptor antagonist Bosentan. Respir Physiol Neurobiol 2010;170:32-36.

20 Jones MG, Fletcher S, Richeldi L: Idiopathic pulmonary fibrosis: recent trials and current drug therapy. Respiration 2013;86:353-363.

21 Mouratis MA, Aidinis V: Modeling pulmonary fibrosis with bleomycin. Curr Opin Pulm Med 2011;17:355-361.

22 Moore BB, Hogaboam CM: Murine models of pulmonary fibrosis. Am J Physiol Lung Cell Mol Physiol 2008;294:L152-L160.

23 Rubinstein I: Prolonged anti-hypertensive effects of oral sitaxsentan, a selective ET(A) endothelin receptor antagonist, in spontaneoulsy hypertensive hamsters. Cardiovasc Drugs Ther 2006;20:387-390.

24 Manali ED, Moschos C, Triantafillidou C, Kotanidou A, Psallidas I, Karabela SP, Roussos C, Papiris S, Armaganidis A, Stathopoulos GT, et al: Static and dynamic mechanics of the murine lung after intratracheal bleomycin. BMC Pulm Med 2011;11:33.

25 Murao Y, Loomis W, Wolf P, Hoyt DB, Junger WG: Effect of dose of hypertonic saline on its potential to prevent lung tissue damage in a mouse model of hemorrhagic shock. Shock 2003;20:29-34.

26 Barst RJ, Langleben D, Frost A, Horn EM, Oudiz R, Shapiro S, McLaughlin V, Hill N, Tapson VF, Robbins IM, et al: Sitaxsentan therapy for pulmonary arterial hypertension. Am J Respir Crit Care Med 2004;169:441447.

27 Rubin LJ, Badesch DB, Barst RJ, Galie N, Black CM, Keogh A, Pulido T, Frost A, Roux S, Leconte I, et al: Bosentan therapy for pulmonary arterial hypertension. $\mathrm{N}$ Engl J Med 2002;346:896-903.

28 Galie N, Hoeper MM, Gibbs JS, Simonneau G: Liver toxicity of sitaxentan in pulmonary arterial hypertension. Eur Respir J 2011;37:475476.

29 Zhu Y, Liu Y, Zhou W, Xiang R, Jiang L, Huang K, Xiao Y, Guo Z, Gao J: A prostacyclin analogue, iloprost, protects from bleomycin-induced pulmonary fibrosis in mice. Respir Res 2010;11:34.

30 Cai GQ, Zheng A, Tang Q, White ES, Chou CF, Gladson CL, Olman MA, Ding Q: Downregulation of FAK-related non-kinase mediates the migratory phenotype of human fibrotic lung fibroblasts. Exp Cell Res 2010;316: 1600-1609.

31 Ding Q, Gladson CL, Wu H, Hayasaka H, Olman MA: Focal adhesion kinase (FAK)-related non-kinase inhibits myofibroblast differentiation through differential MAPK activation in a FAK-dependent manner. J Biol Chem 2008;283:26839-26849.
32 Kulasekaran P, Scavone CA, Rogers DS, Arenberg DA, Thannickal VJ, Horowitz JC: Endothelin-1 and transforming growth factor-beta1 independently induce fibroblast resistance to apoptosis via AKT activation. Am J Respir Cell Mol Biol 2009;41:484-493.

33 Shi-Wen X, Chen Y, Denton CP, Eastwood M, Renzoni EA, Bou-Gharios G, Pearson JD, Dashwood M, du Bois RM, Black CM, et al: Endothelin-1 promotes myofibroblast induction through the ETA receptor via a rac/phosphoinositide 3-kinase/Akt-dependent pathway and is essential for the enhanced contractile phenotype of fibrotic fibroblasts. Mol Biol Cell 2004;15:2707-2719.

34 Vittal R, Horowitz JC, Moore BB, Zhang H, Martinez FJ, Toews GB, Standiford TJ, Thannickal VJ: Modulation of prosurvival signaling in fibroblasts by a protein kinase inhibitor protects against fibrotic tissue injury. Am J Pathol 2005;166:367-375.

35 Cho JJ, Hocher B, Herbst H, Jia JD, Ruehl M, Hahn EG, Riecken EO, Schuppan D: An oral endothelin-A receptor antagonist blocks collagen synthesis and deposition in advanced rat liver fibrosis. Gastroenterology 2000;118: 1169-1178.

36 Zouki C, Baron C, Fournier A, Filep JG: Endothelin-1 enhances neutrophil adhesion to human coronary artery endothelial cells: role of ET(A) receptors and platelet-activating factor. Br J Pharmacol 1999;127:969-979.

37 Kelland NF, Kuc RE, McLean DL, Azfer A, Bagnall AJ, Gray GA, Gulliver-Sloan FH, Maguire JJ, Davenport AP, Kotelevtsev YV, et al: Endothelial cell-specific ETB receptor knockout: autoradiographic and histological characterisation and crucial role in the clearance of endothelin-1. Can J Physiol Pharmacol 2010;88:644-651.

38 Rullman E, Gustafsson T, Ahlborg G: The impact of the endothelin type A receptor on regional endothelin-1 turnover, in particular renal endothelin-1 release, in humans. J Appl Physiol (1985) 2010;108:1625-1630.

39 King TE Jr, Behr J, Brown KK, du Bois RM, Lancaster L, de Andrade JA, Stahler G, Leconte I, Roux S, Raghu G: BUILD-1: a randomized placebo-controlled trial of bosentan in idiopathic pulmonary fibrosis. Am J Respir Crit Care Med 2008;177:75-81.

40 King TE Jr, Brown KK, Raghu G, du Bois RM, Lynch DA, Martinez F, Valeyre D, Leconte I, Morganti A, Roux S, et al: BUILD-3: a randomized, controlled trial of bosentan in idiopathic pulmonary fibrosis. Am J Respir Crit Care Med 2011;184:92-99.

41 Raghu G, Behr J, Brown KK, Egan JJ, Kawut SM, Flaherty KR, Martinez FJ, Nathan SD, Wells AU, Collard HR, et al: Treatment of idiopathic pulmonary fibrosis with ambrisentan: a parallel, randomized trial. Ann Intern Med 2013;158:641-649.
ETA Receptor Inhibition in

Bleomycin-Induced Fibrosis
Respiration 2018;95:122-136

DOI: $10.1159 / 000481201$ 
42 Raghu G, Million-Rousseau R, Morganti A, Perchenet L, Behr J: Macitentan for the treatment of idiopathic pulmonary fibrosis: the randomised controlled MUSIC trial. Eur Respir J 2013;42:1622-1632.

43 Chung MP, Monick MM, Hamzeh NY, Butler NS, Powers LS, Hunninghake GW: Role of repeated lung injury and genetic background in bleomycin-induced fibrosis. Am J Respir Cell Mol Biol 2003;29:375-380.

44 Peng R, Sridhar S, Tyagi G, Phillips JE, Garrido R, Harris P, Burns L, Renteria L, Woods $\mathrm{J}$, Chen L, et al: Bleomycin induces molecular changes directly relevant to idiopathic pulmonary fibrosis: a model for "active" disease. PLoS One 2013;8:e59348.

45 Comellas AP, Briva A: Role of endothelin-1 in acute lung injury. Transl Res 2009;153:263271.

46 Toney BM, Fisher AJ, Albrecht M, Lockett AD, Presson RG, Petrache I, Lahm T: Selective endothelin-A receptor blockade attenuates endotoxin-induced pulmonary hypertension and pulmonary vascular dysfunction. Pulm Circ 2014;4:300-310.

47 Ishizaki T, Shigemori K, Nakai T, Miyabo S, Hayakawa M, Ozawa T, Voelkel NF, Chang SW: Endothelin-1 potentiates leukotoxin-induced edematous lung injury. J Appl Physiol (1985) 1995;79:1106-1111.
48 Carpenter T, Schomberg S, Steudel W, Ozimek J, Colvin K, Stenmark K, Ivy DD: Endothelin $\mathrm{B}$ receptor deficiency predisposes to pulmonary edema formation via increased lung vascular endothelial cell growth factor expression. Circ Res 2003;93:456-463.

49 Helset E, Kjaeve J, Hauge A: Endothelin-1-induced increases in microvascular permeability in isolated, perfused rat lungs requires leukocytes and plasma. Circ Shock 1993;39:1520.

50 Lee CG, Cho SJ, Kang MJ, Chapoval SP, Lee PJ, Noble PW, Yehualaeshet T, Lu B, Flavell RA, Milbrandt J, et al: Early growth response gene 1-mediated apoptosis is essential for transforming growth factor betal-induced pulmonary fibrosis. J Exp Med 2004;200:377389.

51 Sime PJ, Xing Z, Graham FL, Csaky KG, Gauldie J: Adenovector-mediated gene transfer of active transforming growth factor-beta 1 induces prolonged severe fibrosis in rat lung. J Clin Invest 1997;100:768-776.

52 Mitra SK, Hanson DA, Schlaepfer DD: Focal adhesion kinase: in command and control of cell motility. Nat Rev Mol Cell Biol 2005;6: $56-68$.
53 Daher Z, Noel J, Claing A: Endothelin-1 promotes migration of endothelial cells through the activation of ARF6 and the regulation of FAK activity. Cell Signal 2008;20:2256-2265.

54 Lagares D, Busnadiego O, Garcia-Fernandez RA, Kapoor M, Liu S, Carter DE, Abraham D, Shi-Wen X, Carreira P, Fontaine BA, et al: Inhibition of focal adhesion kinase prevents experimental lung fibrosis and myofibroblast formation. Arthritis Rheum 2012;64:16531664.

55 Thannickal VJ, Lee DY, White ES, Cui Z, Larios JM, Chacon R, Horowitz JC, Day RM, Thomas PE: Myofibroblast differentiation by transforming growth factor-betal is dependent on cell adhesion and integrin signaling via focal adhesion kinase. J Biol Chem 2003; 278:12384-12389.

56 Alcorn JF, van der Velden J, Brown AL, McElhinney B, Irvin CG, Janssen-Heininger YM: $c$-Jun $\mathrm{N}$-terminal kinase 1 is required for the development of pulmonary fibrosis. Am J Respir Cell Mol Biol 2009;40:422-432.

57 Vittal R, Fisher A, Gu H, Mickler EA, Panitch A, Lander C, Cummings OW, Sandusky GE, Wilkes DS: Peptide-mediated inhibition of mitogen-activated protein kinase-activated protein kinase- 2 ameliorates bleomycin-induced pulmonary fibrosis. Am J Respir Cell Mol Biol 2013;49:47-57. 